\title{
Arrhythmic complications during percutaneous coronary interventions
}

\section{(i) Ivica Benko ${ }^{1,2 *}$, (D) Gordana Hursa', (DSanja Keleković1, (DTomislav Pijetlović}

'University Hospital Centre "Sestre milosrdnice“, Zagreb, Croatia

2University of Applied Health Sciences, Zagreb, Croatia
RECEIVED:

February 18, 2020

ACCEPTED:

February 22, 2020

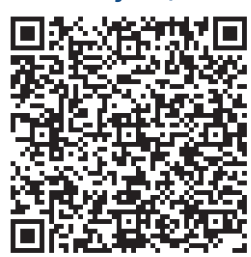

KEYWORDS: cardiac arrhythmias, percutaneous coronary intervention, nursing, guidelines implementation.

CITATION: Cardiol Croat. 2020;15(3-4):61. | https://doi.org/10.15836/ccar2020.61

*ADDRESS FOR CORRESPONDENCE: Ivica Benko, KBC Sestre milosrdnice, Vinogradska 29, HR-10000 Zagreb, Croatia. / Phone: +385-98-1706-082 / E-mail: ivica.benko@kbcsm.hr

ORCID: Ivica Benko, https://orcid.org/0000-0002-1878-0880 • Gordana Hursa, https://orcid.org/0000-0001-9118-9707 Sanja Keleković, https://orcid.org/0000-0003-4951-876X • Tomislav Pijetlović, https://orcid.org/0000-0002-4499-4428

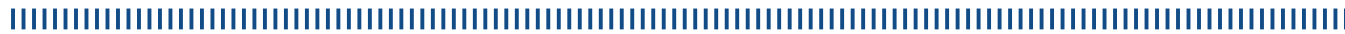

Percutaneous coronary interventions (PCI) have been the fastest-growing major invasive procedure in the past decade. Although PCI has many advantages, there are certain risks, including cardiac arrhythmias. It is known that myocardial ischemia and infarction leads to severe metabolic and electrophysiological changes that induce silent or symptomatic life-threatening arrhythmias. Both atrial and ventricular arrhythmias may occur during PCI procedure. ${ }^{1-3}$ Arrhythmias and conduction disturbances are common during the early hours after myocardial infarction (MI) and a major cause of death in the pre-hospital phase. In STEMI patients undergoing primary PCI, ventricular arrhythmias, including non-sustained ventricular tachycardia (VT) in $26 \%$ of cases and sustained VT in $2-5 \%$ cases, have been reported. As the most lethal arrhythmia, ventricular fibrillation (VF) has been reported in $2-5 \%$ of cases. But on the other side, sustained VT occurs in $17-21 \%$ and VF even in $24-29 \%$ in patients with MI and cardiogenic shock undergoing pPCI. The occurrence of atrial fibrillation (AF) is frequently associated with severe left ventricular damage and heart failure. Episodes may last from minutes to hours and are often repetitive. In the case of cardiogenic shock, AF can quickly lead to a worsening of symptoms. High-grade AV block and asystole develop in about 23-35\% of acute MI patients with cardiogenic shock, especially in the case of right coronary artery occlusion. Either ventricular or atrial arrhythmias or conduction disturbances occur as a complication of the PCI procedure, but many of them are related to reperfusion injury. The majority of the arrhythmias tend to revert spontaneously, but when necessary, special treatment must be given promptly. For nurses to be able to react properly, effective and early recognition of cardiac arrhythmias during PCI is crucial and beneficial. Also, it is important to identify changes in cardiac status and to early recognize high-risk patients for cardiac arrest, before the patient becomes symptomatic. Accuracy of cardiac rhythm interpretation improves with intermittent educational interventions. Moreover, cardiac rhythm recognition is crucial during Advance Life Support (ALS) training and it is recommended for all cardiac catheterization staff to undergo this type of training.
LITERATURE IIIIIIIIIIIIIIIIIIIIIIIIIIIIIIIIIIIIIIIIIIIIIIIIIIIIIIIIIIIIIIIIIIIIIIIIIIIIIIIIIIIIIIIIIIIIIIIIIIII

1. Gorenek B, Blomström Lundqvist C, Brugada Terradellas J, Camm AJ, Hindricks G, Huber K, et al. Cardiac arrhythmias in acute coronary syndromes: position paper from the joint EHRA, ACCA, and EAPCI task force. Europace. 2014 Nov:16(11):1655-73. https://doi.org/10.1093/europace/euu208

2. French JK, Armstrong PW, Cohen E, Kleiman NS, O'Connor CM, Hellkamp AS, et al. Cardiogenic shock and heart failure post-percutaneous coronary intervention in ST-elevation myocardial infarction: observations from "Assessment of Pexelizumab in Acute Myocardial Infarction". Am Heart J. 2011 Jul;162(1):89-97. https://doi.org/10.1016/j.ahj.2011.04.009

3. Terkelsen CJ, Sørensen JT, Kaltoft AK, Nielsen SS, Thuesen L, Bøtker HE, et al. Prevalence and significance of accelerated idioventricular rhythm in patients with ST-elevation myocardial infarction treated with primary percutaneous coronary intervention. Am J Cardiol. 2009 Dec 15:104(12):1641-6. https://doi.org/10.1016/j.amjcard.2009.07.037 